\title{
Co-Existent Intrauterine and Ectopic Tubal Pregnancy
}

\author{
Colonel K D Printer MB FRCOG L/RAMC
}

Consultant Obstetrician and Gynaecologist

Princess Alexandra Hospital, Royal Air Force, Wroughton, Swindon

SUMMARY: A case of co-existent intrauterine and ectopic pregnancy is described in a patient from overseas. The difficulty in diagnosis and management is discussed, together with recent literature.

\section{Case Report}

The patient, aged 40 years, para $2+0$, and on holiday in the UK from overseas, was admitted to hospital as an emergency with a history of acute lower abdominal pains of four days' duration. Her last menstrual period began nine weeks before the onset of pain.

An ectopic pregnancy was diagnosed clinically and at laparotomy a right tubal pregnancy found. Three pints of blood was noted in the abdomen. Right salpingectomy was done. The uterus was noted to be bulky, but no D \& C was performed. She was discharged some eight days later and returned overseas. Histology subsequently confirmed the presence of a tubal pregnancy.

She visited her local GP overseas two months after her operation as she thought she was putting on weight. She had not had any vaginal bleeding since her right salpingectomy. She was given Tenuate Dospan. About a week later she revisited her GP complaining of lower abdominal pains and a slight brown vaginal discharge. On examination then to everyone's surprise she was found to be about 20 weeks pregnant! She had had intercourse for the first time since her operation three months postoperatively. In view of her age and circumstances, a request for consideration of termination of pregnancy was forwarded and the patient was transferred from overseas to the UK five weeks later.

On examination on arrival from overseas she was found to be 24 weeks pregnant. Termination at this stage was thought to be unwise. Adoption was suggested and the patient readily agreed to this and the pregnancy continued normally. Forty weeks after her last menstrual period, or thirty weeks after her operation she had a normal vaginal delivery of a live healthy male infant, weighing $2.95 \mathrm{~kg}$. The baby was adopted and she returned home following a Pomeroy's sterilization operation.

\section{Discussion}

The co-existence of ectopic and intrauterine pregnancy has been thought to be rare. For example, according to Beckmann, Tomasi \& Thomason ${ }^{1}$, the incidence of this has been reported as between one in 15,000 to one in 30,000 pregnancies. Hann, Bachmann and $\mathrm{McArdle}^{2}$ reported the possibility of intrauterine fetus surviving as one in three to one in two cases. In this case twins were conceived, one in the tube and one in utero. The ectopic tubal pregnancy was easily diagnosed and treated. The possibility of a co-existing intrauterine pregnancy was not entertained, even though there was no vaginal bleeding at the time of or after salpingectomy. It was a surprise when, following her return to her home abroad the patient was found to be 20 weeks pregnant. With hindsight, the size of the uterus was compatible with the period of amenorrhea. The ruptured ectopic occurred when she was about eight weeks pregnant.

Recent gynaecological literature indicates that this condition may be more common than originally thought. A re-appraisal of simultaneous intra- and extra-uterine pregnancy done by Richards, Stempel \& Carlton showed an actual incidence of one in 2600 pregnancies $\stackrel{\mathbb{P}}{\square}$ Cases reported from Beth Israel Hospital ${ }^{2}$ show aID incidence of one in 6778 pregnancies. This increase $\mathbb{E}$ incidence is thought to be due to a number of factors including the increased incidence of ectopic pregnanc (0.5 to 1.1 of all pregnancies), the use of ovulatiof inducing drugs, the increased incidence of pelvie inflammatory diseases, the trend for delay in childbearing to the later reproductive years, and the higher incidence of endometriosis which can inhibit oviduct motility by peritubal endometrial deposits and adhesions ${ }^{4}$.

According to Hayes \& Haley $y^{5}$ a high index of clinical suspicion is necessary to diagnose this condition. Patients with persistent adnexal pain after termination of intrauterine pregnancy or those who fail to shed decidua after surgery for an ectopic pregnancy, should be suspected of having a concurrent intra- and extrauterine pregnancy. The modern ultrasound examination is a very potent tool in the diagnosis of this condition. It is important to remember that ultrasonic demonstration of an intrauterine gestational fetal sac does not necessarily preclude a simultaneous extrauterine pregnancy and vice versa.

It was not possible to establish by the methods recommended by Hayes and Haley ${ }^{5}$ whether this was a case of superfecundation, ie two separate pregnancies from two ovulations in the same cycle, or superfoetation, ie two separate pregnancies from two ovulations in separate menstrual cycles.

\section{Acknowledgement}

My thanks to Miss Jane Sayle, Medical Librarian, RAF Halton, for help with the references, to Mrs 
Margaret Link for the typing of the manuscript, and Mr McDonald, Surgical Registrar at Southampton for medical information.

\section{REFERENCES}

1. Beckmann C, Tomasi A and Thomason J. Combined Interstitial and Uterine Pregnancy. Am $J$ Obstet Gynaecol 1984; 149: 83-85.
2. Hann L, BaChManN D, and MCardle C. Co-existent Intrauterine and Ectopic Pregnancy: A Revaluation. Radiology 1984; 152: 151-154.

3. Richards S, Stempel L and Carlton B. Heterotopic 으 Pregnancy: Reappraisal of Incidence $A m J$ Obstet Gynaecol 1982; 142(7): 928-930.

4. Jones $H$, Jr and Jones G. Endometriosis. NOVAK's Textbook of Gynaecology 1981: 626.

5. HAYES $H$ and HaLEY E. Intrauterine and Ruptured $\frac{\sigma}{\sigma}$ Tubal Ectopic Pregnancy. Ann Emerg Med (US) 1984; ज̄ 13: $355-358$.

\section{ACADEMIC ACHIEVEMENTS}

Fellowship of the Royal College of Physicians

Degree of Doctor of Medicine of the University of Newcastle-upon-Tyne

Final Fellowship in Otolaryngology at The Royal College of Surgeons of Edinburgh

Membership of the Faculty of Community Medicine-Pt II

Diploma of Industrial Health

Associate in the Faculty of Occupational Medicine

Diploma of Tropical Medicine and Hygiene, Liverpool

Diploma in Tropical Medicine and Hygiene, Liverpool

Diploma of the Royal College of Obstetricians and Gynaecologists

Diploma in Child Health

DRCOG

FFARCSI

FRCSI

MRCGP
Col D S Jolliffe, L/RAMC

Lt Col R P Craig, RAMC

Major J A J Deans, RAMC

Col C G Callow, RAMC

Major M G Braithwaite, RAMC

Major M G Braithwaite, RAMC

Major J F Navein, RAMC

Captain R T A Walker, RAMC

Captain P A Johnson, RAMC

Captain C Grummitt, RAMC Major CSidebotham, RAMC Major J F Navein, RAMC

Captain J Barrel, RAMC Captain A Rixom, RAMC Captain P Travis, RAMC

Major I G Johnson, RAMC

Major J D C Bennett, RAMC

Captain G M Allan, RAMC Major G J Hayes, RAMC Capt C A J Hodson, RAMC Major K D Jones, RAMC Captain J W McCorkindale, RAMC Captain J J McPeake, RAMC Major M A Staunton, RAMC 